\title{
Enhanced Optical Properties of Germanate and Tellurite Glasses Containing Metal or Semiconductor Nanoparticles
}

\author{
Cid Bartolomeu de Araujo, ${ }^{1}$ Diego Silvério da Silva, \\ Thiago Alexandre Alves de Assumpção, ${ }^{2}$ Luciana Reyes Pires Kassab, ${ }^{3}$ \\ and Davinson Mariano da Silva ${ }^{3}$ \\ ${ }^{1}$ Departamento de Física, Universidade Federal de Pernambuco, 50740-540 Recife, PE, Brazil \\ ${ }^{2}$ Departamento de Engenharia de Sistemas Eletrônicos, Escola Politécnica da USP, 05508-900 São Paulo, SP, Brazil \\ ${ }^{3}$ Laboratório de Tecnologia em Materiais Fotônicos e Optoeletrônicos, Faculdade de Tecnologia de São Paulo, CEETEPS/UNESP, \\ 01124-060 São Paulo, SP, Brazil
}

Correspondence should be addressed to Luciana Reyes Pires Kassab; kassablm@osite.com.br

Received 14 December 2012; Accepted 17 January 2013

Academic Editors: R. Pode, P. D. Sahare, and D. Zhang

Copyright (c) 2013 Cid Bartolomeu de Araujo et al. This is an open access article distributed under the Creative Commons Attribution License, which permits unrestricted use, distribution, and reproduction in any medium, provided the original work is properly cited.

\begin{abstract}
Germanium- and tellurium-based glasses have been largely studied due to their recognized potential for photonics. In this paper, we review our recent studies that include the investigation of the Stokes and anti-Stokes photoluminescence (PL) in different glass systems containing metallic and semiconductor nanoparticles (NPs). In the case of the samples with metallic NPs, the enhanced PL was attributed to the increased local field on the rare-earth ions located in the proximity of the NPs and/or the energy transfer from the metallic NPs to the rare-earth ions. For the glasses containing silicon NPs, the PL enhancement was mainly due to the energy transfer from the NPs to the $\mathrm{Er}^{3+}$ ions. The nonlinear (NL) optical properties of $\mathrm{PbO}-\mathrm{GeO}_{2}$ films containing gold NPs were also investigated. The experiments in the pico- and subpicosecond regimes revealed enhanced values of the NL refractive indices and large NL absorption coefficients in comparison with the films without gold NPs. The reported experiments demonstrate that germanate and tellurite glasses, having appropriate rare-earth ions doping and NPs concentration, are strong candidates for PLbased devices, all-optical switches, and optical limiting.
\end{abstract}

\section{Introduction}

Suitable composites for photonic applications have to present large transmittance, high refractive index, low cut-off phonon energy, and large nonlinear optical response. Germanate and tellurite glasses have these characteristics and were identified as good hosts for trivalent rare-earth ions (REI) and metal or semiconductor nanoparticles (NPs) [1-12]. In these glasses, the linear and nonlinear optical properties may be largely enhanced due to the presence of the NPs. Specifically, in glasses containing metal NPs when the incident light or the photoluminescence (PL) wavelengths are near the localized surface plasmon resonance (LSPR) wavelength, $\lambda_{\mathrm{SP}}$, a large PL enhancement may occur. In principle, $\lambda_{\mathrm{SP}}$ depends on the host and metal dielectric functions as well as on the dimensions and shape of the NPs. The PL efficiency of a composite for a given incident wavelength depends on the LSPR, the NPs concentration, and the density of phonon states in the host material. In particular, REI doped glasses containing metallic NPs have been investigated because their luminescence may be intensified by energy transfer from the metallic NPs and/or due to enhancement of the local field that acts on the REI located in the proximity of the NPs $[10,11]$. On the other hand, glasses containing silicon NPs (semiconductor quantum dots) may act as efficient absorbers, and the energy stored in the Si NPs may be transferred to REI, and thus they may contribute for PL enhancement in various wavelengths ranges that can be selected controlling the quantum dots sizes. Some evidence of this effect was reported long ago for silicon-rich silica glass [13-16]. 
TABLE 1: Composition and parameters used for production of the glass samples. M/A refer to melting/annealing.

\begin{tabular}{lcccc}
\hline Sample & Glass composition (wt.\%) & Dopants (wt.\%) & M/A temperature $\left({ }^{\circ} \mathrm{C}\right)$ & $\mathrm{M} / \mathrm{A}$ time $(\mathrm{h})$ \\
\hline PGO-Er/Yb:Ag & $40.3 \mathrm{GeO}_{2}-59.7 \mathrm{PbO}$ & $0.5 \mathrm{Er}_{2} \mathrm{O}_{3}-3.0 \mathrm{Yb}_{2} \mathrm{O}_{3}-1.0 \mathrm{AgNO}_{3}$ & $1200 / 420$ & $1 / 2$ \\
PGO-Eu:Ag & $40.3 \mathrm{GeO}_{2}-59.7 \mathrm{PbO}$ & $0.5 \mathrm{Eu}_{2} \mathrm{O}_{3}-3.0 \mathrm{AgNO}_{3}$ & $1200 / 420$ & $1 / 3$ \\
BGO-Eu:Au & $58.4 \mathrm{GeO}_{2}-41.6 \mathrm{Bi}_{2} \mathrm{O}_{3}$ & $0.5 \mathrm{Eu}_{2} \mathrm{O}_{3}-3.0 \mathrm{Au}_{2} \mathrm{O}_{3}$ & $1100 / 420$ & $1 / 3$ \\
BGO-Er:Si & $58.4 \mathrm{GeO}_{2}-41.6 \mathrm{Bi}_{2} \mathrm{O}_{3}$ & $0.5 \mathrm{Er}_{2} \mathrm{O}_{3}-0.2 \mathrm{Si}$ nanopowder & $1100 / 420$ & $1 / 3$ \\
TZO-Er:Ag & $85.0 \mathrm{TeO}_{2}-15.0 \mathrm{ZnO}$ & $0.5 \mathrm{Tm}_{2} \mathrm{O}_{3}-2.0 \mathrm{AgNO}_{3}$ & $800 / 325$ & $20 / 2$ \\
TWB-Er:Ag & $54.5 \mathrm{TeO}_{2}-22.6 \mathrm{WO}_{3}-22.7 \mathrm{Bi}_{2} \mathrm{O}_{3}$ & $1.0 \mathrm{Er}_{2} \mathrm{O}_{3}-2.0 \mathrm{AgNO}_{3}$ & $760 / 360$ & $45 / 1$ \\
\hline
\end{tabular}

The first report on nucleation of silver NPs in germanate glasses $\left(\mathrm{PbO}-\mathrm{GeO}_{2}\right)$ was presented in [17], whereas the possibility of production of silver NPs in tellurite glasses was published for the first time in [18]. Also it was reported for the first time the nucleation of copper NPs in $\mathrm{PbO}-\mathrm{GeO}_{2}$ thin films for applications in all-optical switching [19]. The various studies reported for germanate and tellurite glasses, with metallic NPs and different REI, demonstrated the large potential of these materials for photonic applications. On the other hand, the influence of Si NPs on the PL properties of glasses remains a unexploited subject. Recently, we developed a procedure to nucleate Si NPs in germanate glasses that was very efficient to improve the PL properties of germanate glasses.

In this paper, we review recent experiments based on the nucleation of $\mathrm{Ag}, \mathrm{Au}$, and Si NPs in germanate and tellurite bulk glasses containing REI and discuss the optical behavior of the samples under different excitation conditions. Besides the work with bulk samples, the production of germanate thin films using the radio-frequency sputtering technique is also reported. The nucleation of gold NPs in the films is described, and a study of the NPs influence on the films' nonlinear optical properties is presented.

The paper is organized as follows. In Section 2, we describe the fabrication methods and the characterization techniques used to study the samples. In Section 3, the structural characteristics of the samples as well as their optical characteristics are discussed. Finally in Section 4, we comment on the perspectives of applications for the kind of composites discussed here.

\section{Methods}

2.1. Production of the Bulk Samples. Germanate $\left(\mathrm{GeO}_{2}-\right.$ $\mathrm{PbO}$ and $\left.\mathrm{GeO}_{2}-\mathrm{Bi}_{2} \mathrm{O}_{3}\right)$ and telurite $\left(\mathrm{TeO}_{2}-\mathrm{ZnO}\right.$ and $\mathrm{TeO}_{2}$ $\mathrm{WO}_{3}-\mathrm{Bi}_{2} \mathrm{O}_{3}$ ) glasses were prepared with high-purity reagents (99.999\%) using the melt-quenching method followed by adequate heat treatment (HT) that depends on the transition temperature of each glass composition. The compositions studied are shown in Table 1 as well as the parameters used in the fabrication process.

The reagents were melted in crucibles made of platinum (for the tellurite glasses) or alumina (for the germanates). Mechanical stirring during the melting was applied to germanate glasses, to optimize transparency and homogeneity. After cooling to room temperature inside the furnace, the samples were polished, cut, and then submitted to additional
HT to nucleate metallic NPs (metallic ions $\mathrm{Ag}^{+}$and $\mathrm{Au}^{+}$from $\mathrm{AgNO}_{3}$ and $\mathrm{Au}_{2} \mathrm{O}_{3}$ are reduced to $\mathrm{Ag}^{0}$ and $\mathrm{Au}^{0}$, resp., for nucleation of the NPs). Samples without metallic NPs were also fabricated to be used as reference.

The melt-quenching technique was also used for the fabrication of the samples with silicon quantum dots mixing Si nanograins having average diameter of $100 \mathrm{~nm}$ with the base germanate glass constituents. The starting reagents were melted inside an alumina crucible for $1 \mathrm{~h}$ at $1200^{\circ} \mathrm{C}$, quenched in air in a preheated brass mold, and annealed at $420^{\circ} \mathrm{C}$ to minimize internal stress. Finally, the glasses were cooled to room temperature inside the furnace. After cooling, the samples' surfaces were polished to optical quality. Samples without $\mathrm{Si}-\mathrm{NCs}$ and doped with $\mathrm{Er}^{3+}$ were also fabricated to be used as reference. Transparent glasses stable against crystallization were produced. The density of Si-NCs was controlled by heat-treating the samples for time intervals of 3,48 , and 72 hours, at $420^{\circ} \mathrm{C}$.

2.2. Production of the Thin Film Samples. The production of noncrystalline films with and without gold NPs was made by RF sputtering (at $13.56 \mathrm{MHz}$ ) under 5.0 mTorr of argon. For the glass target preparation, the oxide powders were mixed and then submitted to 8 tons uniaxial press. Then, sinterization at $750^{\circ} \mathrm{C}$, for $10 \mathrm{~h}$, was performed followed by $\mathrm{HT}$ at $370^{\circ} \mathrm{C}$, at room atmosphere. The films without NPs were prepared using a target with the composition $40 \mathrm{GeO}_{2}$ $60 \mathrm{PbO}$ (in wt $\%$ ). The films with gold NPs were prepared using the same glass target and a metallic gold target (purity of $99.99 \%$ ). The two targets were simultaneously sputtered. The films were deposited on silica substrates placed $15 \mathrm{~cm}$ far from the targets. The RF power applied in each target was $50 \mathrm{~W}$ for the $\mathrm{GeO}_{2}$-PbO target and $6 \mathrm{~W}$ for the gold target; the deposition time was set to obtain films with thickness of $\approx 1.0 \mu \mathrm{m}$. The HT of the films was performed during different times and temperatures to nucleate the gold NPs.

\subsection{Techniques Employed for Characterization of the Samples.} To investigate the size and shape of the NPs, a Transmission Electron Microscope (TEM) operating at $200 \mathrm{kV}$ and a high-resolution transmission electron microscope (HRTEM) operating at $300 \mathrm{kV}$ were used. electron diffraction measurements were performed to confirm the crystalline structure of the NPs.

All optical measurements were made at room temperature. 


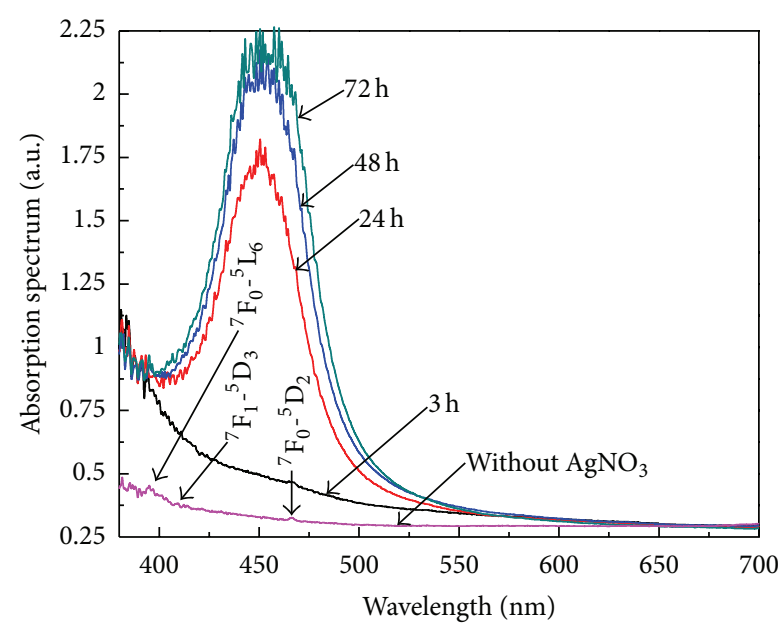

(a)

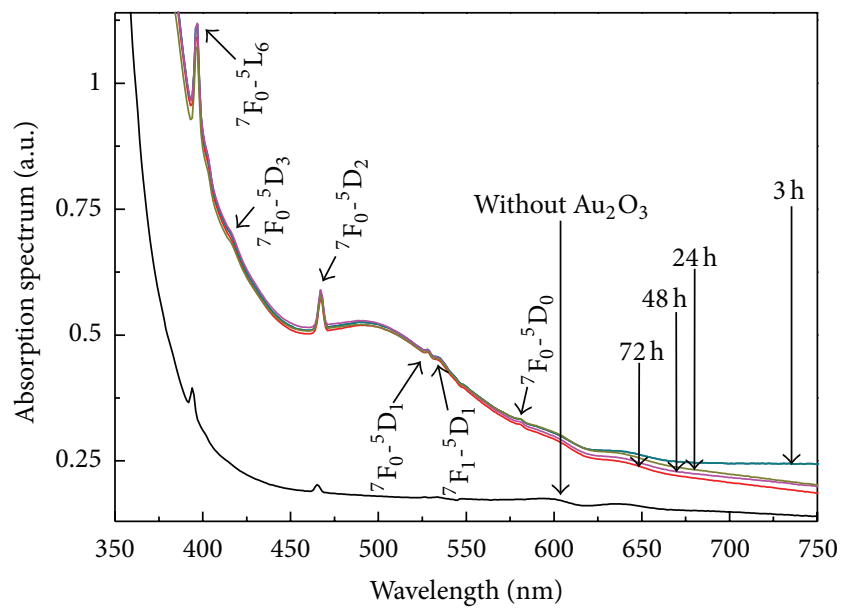

(b)

FIgURE 1: Absorption spectra of the $\mathrm{Eu}^{3+}$ doped samples heattreated during different times. (a) PGO-Eu:Ag. (b) BGO-Eu:Au. Also presented are the spectra of both glasses without metallic NPs [1].

A spectrophotometer that operates in the visible and near-infrared regions was used to measure the absorption spectra of the samples.

PL spectra were measured with different kinds of excitation sources, depending on the sample. In the case of the $\mathrm{Eu}^{3+}$ doped samples, excitation at $405 \mathrm{~nm}$ was obtained from a $15 \mathrm{~W}$ xenon lamp followed by a $0.25 \mathrm{~m}$ monochromator equipped with a holographic grating and the signals were analyzed by a phase fluorometer. For the $\mathrm{Er}^{3+}$ doped samples, a CW $980 \mathrm{~nm}$ diode laser and an ytterbium laser operating at $1050 \mathrm{~nm}$ were used. For the $\mathrm{Tm}^{3+}$ doped samples, an $\mathrm{Nd}^{3+}$ : YVO laser operating at $1047 \mathrm{~nm}$ was utilized the acquisition of signals was obtained with a monochromator with a photomultiplier connected to a lock-in and a computer.

The nonlinear measurements at $532 \mathrm{~nm}$ were made using the second harmonic of a Nd: YAG laser (Q-switched and mode-locked), coupled to a pulse selector for experiments with single pulses of $80 \mathrm{ps}$ at $7 \mathrm{~Hz}$. The Z-scan technique

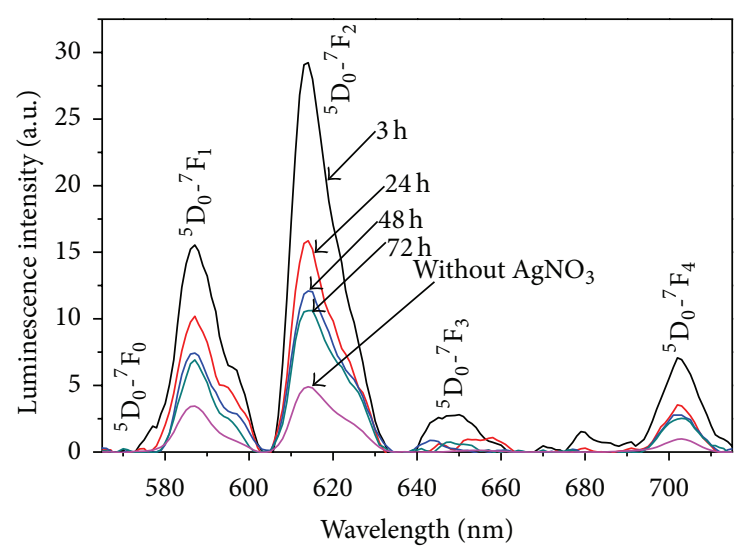

(a)

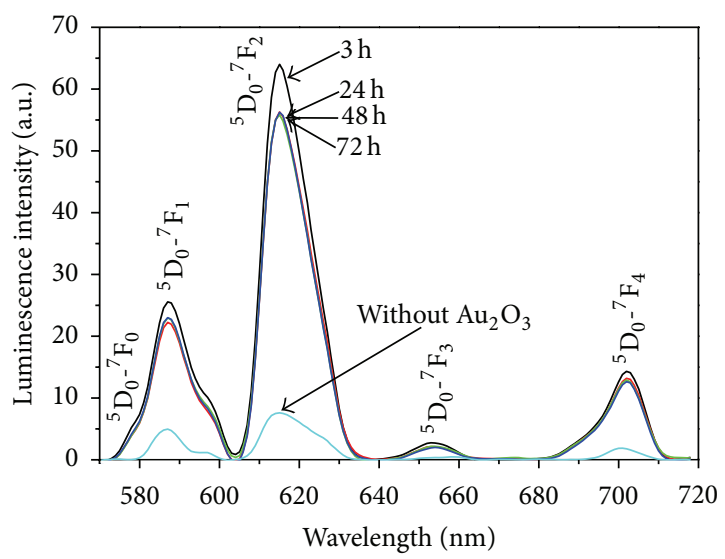

(b)

FIGURE 2: Luminescence spectra of the $\mathrm{Eu}^{3+}$ doped samples heattreated for different times. (a) PGO-Eu:Ag. (b) BGO-Eu:Au. Also presented are the spectra of both glasses without metallic NPs. Excitation wavelength: $405 \mathrm{~nm}$ [1].

[20] was used to measure the nonlinear refractive index and nonlinear absorption coefficient of the samples. The response time of the nonlinearity was determined by a Kerr gate setup [21] based on a Ti-sapphire laser ( $800 \mathrm{~nm} ; 76 \mathrm{MHz} ; 150 \mathrm{fs})$ as the light source. The signals were processed using a boxcar and a computer.

\section{Results}

3.1. Luminescence of Bulk PGO-Eu:Ag and BGO-Eu:Au. The influence of the metallic NPs on electric-dipole and magnetic-dipole transitions of $\mathrm{Eu}^{3+}$ doped germanate glasses was studied in PGO-Eu:Au and BGO-Eu:Au samples with various NPs concentrations and their absorption spectra are shown in the Figures 1(a) and 1(b).

An absorption band in the blue-yellow region is a strong evidence of the nucleation of a large density of metallic NPs. In Figure 1(a) the band centered at $\approx 450 \mathrm{~nm}$ is attributed to the LSPR of the silver NPs. Notice that the band amplitude increases for longer HT times, indicating that the density of NPs is also increasing. Figure 1(b) exhibits a broad absorption 


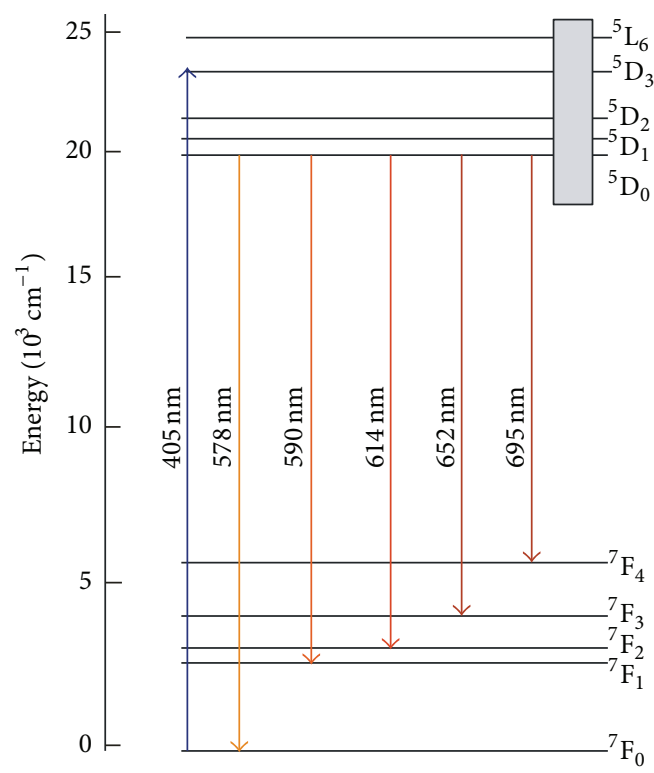

Figure 3: Simplified energy levels scheme of $\mathrm{Eu}^{3+}$ ions with indication of the radiative transitions observed. The shaded area indicates the position of the localized surface plasmon band [1].

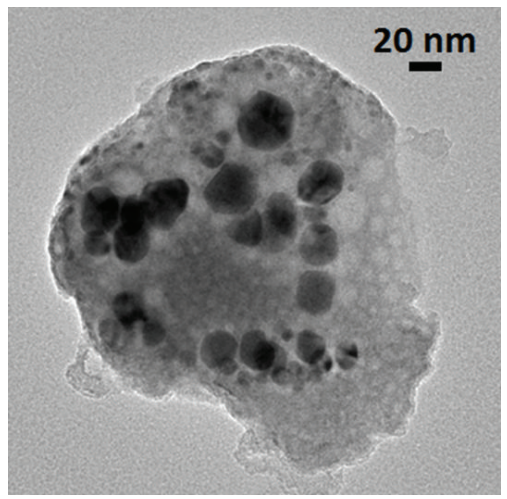

(a)

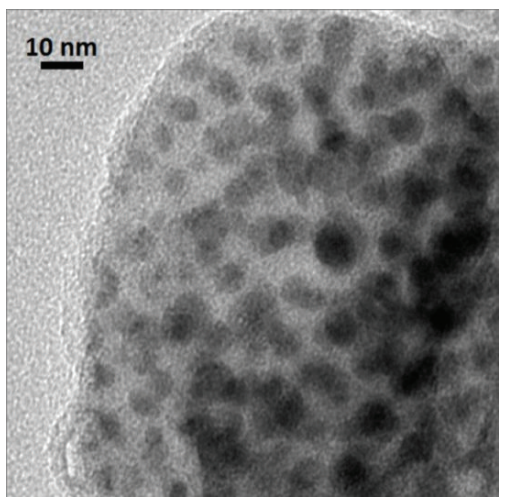

(b)

FIgURE 4: TEM image of the $\mathrm{Eu}^{3+}$ doped samples: (a) $\mathrm{GeO}_{2}-\mathrm{PbO}$ glass with silver NPs heat-treated for 72 hours, (b) $\mathrm{GeO}_{2}-\mathrm{Bi}_{2} \mathrm{O}_{3}$ glass with gold NPs heat-treated for 24 hours [1].

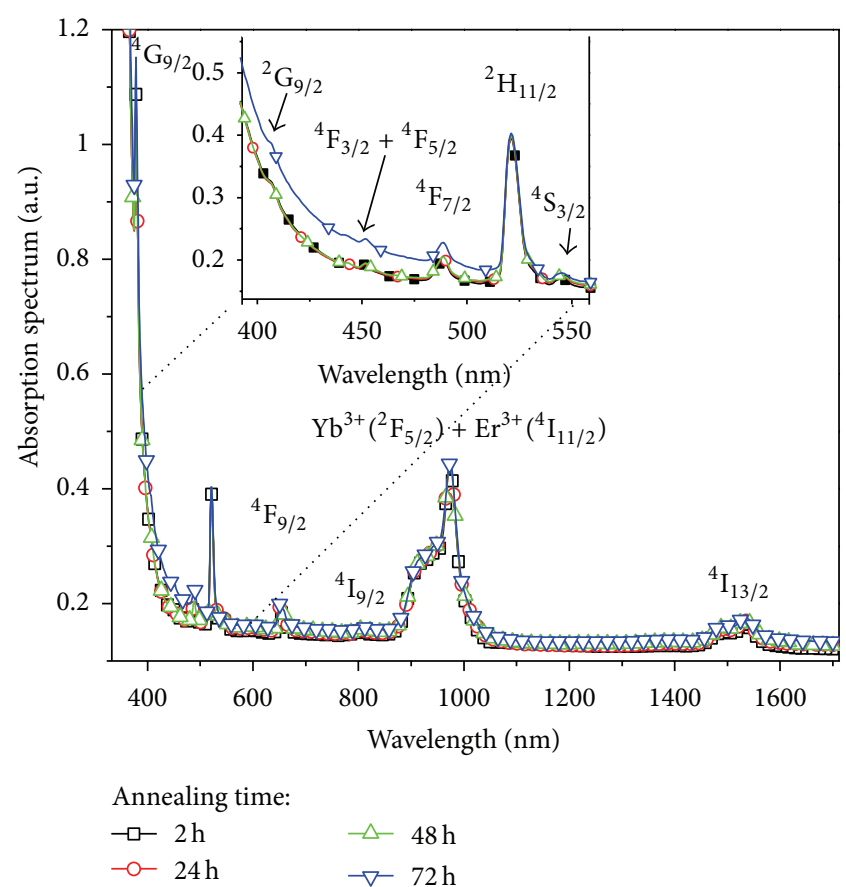

FIGURE 5: Absorption spectra of PGO-Er/Yb:Ag glasses containing silver NPs for different heat-treatment times [2].

band centered at $\approx 500 \mathrm{~nm}$ and a background that extends toward the near infrared, due to the LSPR of the gold NPs and their aggregates.

PL spectra of the same samples for excitation at $405 \mathrm{~nm}$ are shown in the Figures 2(a) and 2(b).

The spectra consist of the $4 f-4 f$ transitions associated to the Eu ${ }^{3+}$ ions: ${ }^{5} \mathrm{D}_{0}{ }^{-}{ }^{7} \mathrm{~F}_{1}(585 \mathrm{~nm}),{ }^{5} \mathrm{D}_{0^{-}}{ }^{7} \mathrm{~F}_{2}(614 \mathrm{~nm}),{ }^{5} \mathrm{D}_{0}{ }^{-} \mathrm{F}_{3}$ $(650 \mathrm{~nm})$, and ${ }^{5} \mathrm{D}_{0}-{ }^{7} \mathrm{~F}_{4}(700 \mathrm{~nm})$. The results indicate that the PL amplitudes are affected by the presence of the metallic NPs, for both samples.

It is clearly noticed that the samples with either silver or gold NPs reach maximum PL enhancement for HT during 3 hours; for longer HT times, it is observed the quenching of the PL spectra for both samples. This behavior is understood considering that with the increasing of the HT time, more $\mathrm{Eu}^{3+}$ ions become so near from the NPs that energy transfer occurs from the directly excited ions to the NPs. The quenching phenomenon occurs because of shortdistance $\mathrm{Eu}^{3+}$-NPs the dipole-dipole interaction between the ion and an NP becomes large [22].

A simplified energy diagram of the $\mathrm{Eu}^{3+}$ ion is shown in Figure 3. Notice that the excitation and the PL wavelengths are near resonance with the LSPR.

Figure 4 shows the TEM images of both samples with a distribution of nearly spherical NPs that contributes to the relatively narrow LSPR bands observed in the absorbance spectra.

In conclusion, we emphasize that nucleation of large concentrations of silver or gold NPs was obtained in $\mathrm{Eu}^{3+}$ doped germanate glasses as illustrated by the strong absorption band associated to the LSPR. Notice that the presence of silver or 


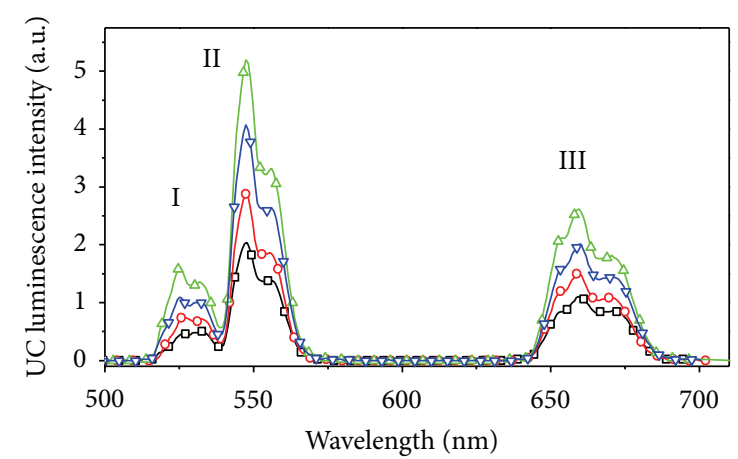

$\begin{array}{ll}\text { Annealing time: } & \\ \rightarrow-2 \mathrm{~h} & \rightarrow-48 \mathrm{~h} \\ \rightarrow-24 \mathrm{~h} & \rightarrow-72 \mathrm{~h}\end{array}$

(a)

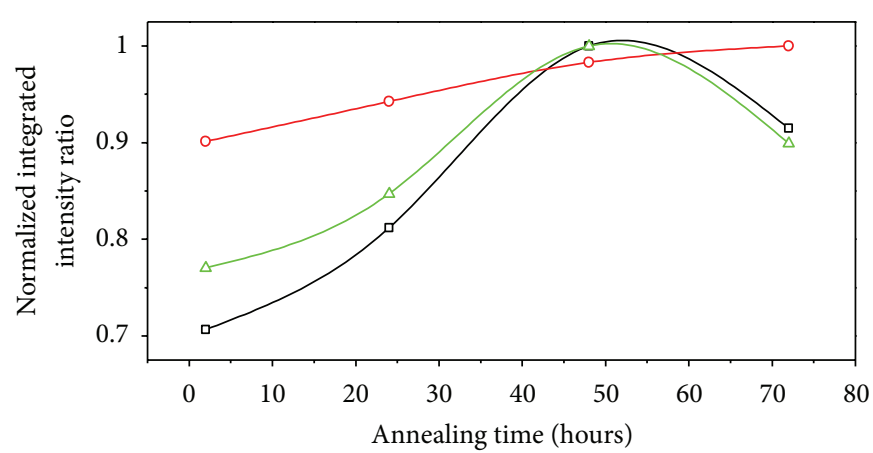

Containing $\mathrm{AgNO}_{3}$

$$
\rightarrow \mathrm{UC}_{\mathrm{I}} / \mathrm{UC}_{\mathrm{III}}
$$$$
\rightarrow \mathrm{UC}_{\mathrm{II}} / \mathrm{UC}_{\mathrm{III}}
$$$$
-\triangle \mathrm{UC}_{\mathrm{I}} / \mathrm{UC}_{\mathrm{II}}
$$

(b)

Figure 6: (a) Frequency upconversion spectra of the of $\mathrm{Er}^{3+} / \mathrm{Yb}^{3+}$ codoped $\mathrm{PbO}-\mathrm{GeO}_{2}$ glasses containing silver NPs for different heattreatment times. (b) Normalized integrated upconversion intensity $\left(\mathrm{UC}_{\mathrm{I}}\right.$ : peak centered at $525 \mathrm{~nm}, \mathrm{UC}_{\mathrm{II}}$ : peak centered at $550 \mathrm{~nm}$, and $\mathrm{UC}$ III: peak centered at $662 \mathrm{~nm}$ ) as a function of the annealing time [2].

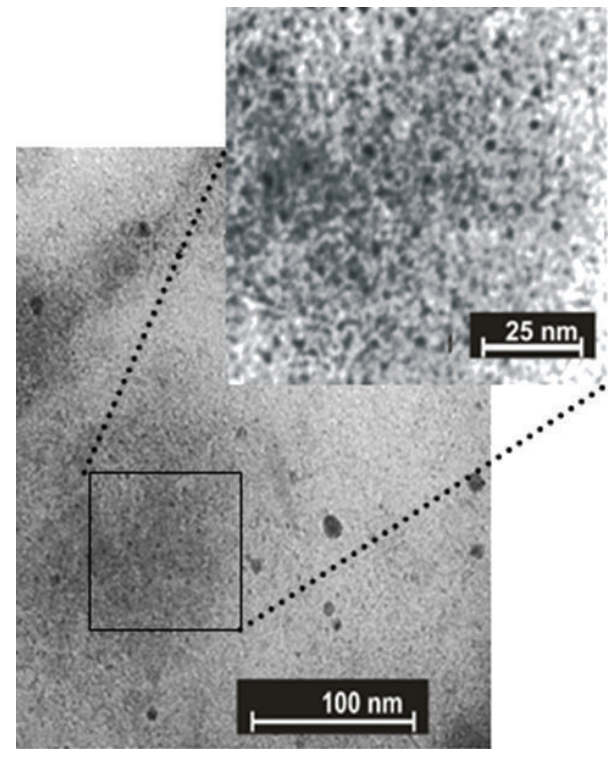

FIgURE 7: TEM images of the samples annealed during $48 \mathrm{~h}$ at $420^{\circ} \mathrm{C}$ [2].

gold NPs in the glasses produces a large PL enhancement. Our results are understood considering the energy transfer process from the metallic NPs to the ions and the enhancement of the confined electromagnetic field in the vicinity of the NPs. The PL intensity enhancement associated to magnetic dipole transitions $\left({ }^{5} \mathrm{D}_{0}-{ }^{7} \mathrm{~F}_{1}\right)$ of $\mathrm{Eu}^{3+}$ ions are due to the confined optical magnetic field. Comparisons of the results for the mixed electric-dipole magnetic-dipole transition $\left({ }^{5} \mathrm{D}_{0}-{ }^{7} \mathrm{~F}_{3}\right)$ with the relative growth of the ${ }^{5} \mathrm{D}_{0}-{ }^{7} \mathrm{~F}_{2}$ transition indicate that the influence of optical magnetic field is relevant also in this case. In other words, although the magnetic response at optical frequencies is usually weak, the location

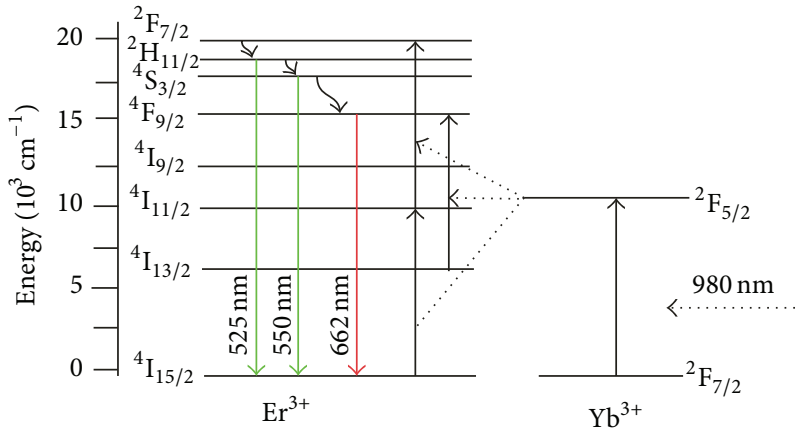

FIGURE 8: Energy level diagram of $\mathrm{Er}^{3+}$ and $\mathrm{Yb}^{3+}$ ions illustrating possible upconversion pathways for $\mathrm{Er}^{3+} / \mathrm{Yb}^{3+}$ codoped glasses. The solid straight lines with upward and down arrows indicate optical transitions; dotted lines and wavy arrows denote ET processes and non-radiative relaxation, respectively [2].

of europium ions in a region where the electromagnetic field is confined contributes for the increase in the signals associated to magnetic dipole transitions. Furthermore, the $1000 \%$ enhancement of the PL corresponding to transition ${ }^{5} \mathrm{D}_{0}-{ }^{7} \mathrm{~F}_{2}$ is a remarkable result [1].

3.2. Energy Transfer and Frequency Upconversion in Bulk $\mathrm{PGO}-\mathrm{Er} / \mathrm{Yb}$ :Ag. The energy transfer and frequency upconversion processes in $\mathrm{Yb}^{3+} / \mathrm{Er}^{3+}$ doped $\mathrm{PbO}-\mathrm{GeO}_{2}$ glass were studied in the samples containing silver NPs. The excitation wavelength was $980 \mathrm{~nm}$ in resonance with the $\mathrm{Yb}^{3+}$ transition ${ }^{2} \mathrm{~F}_{7 / 2}{ }^{2} \mathrm{~F}_{5 / 2}$. The efficient energy transfer from resonantly excited $\mathrm{Yb}^{3+}$ to $\mathrm{Er}^{3+}$ and the influence of the Ag NPs contributed to large enhancement of the whole upconverted spectrum. Absorption and emission spectra of the PGO$\mathrm{Er} / \mathrm{Yb}: \mathrm{Ag}$ samples for different $\mathrm{HT}$ times are shown in Figures 5 and 6(a) respectively. Emission bands centered at 525, 550, 


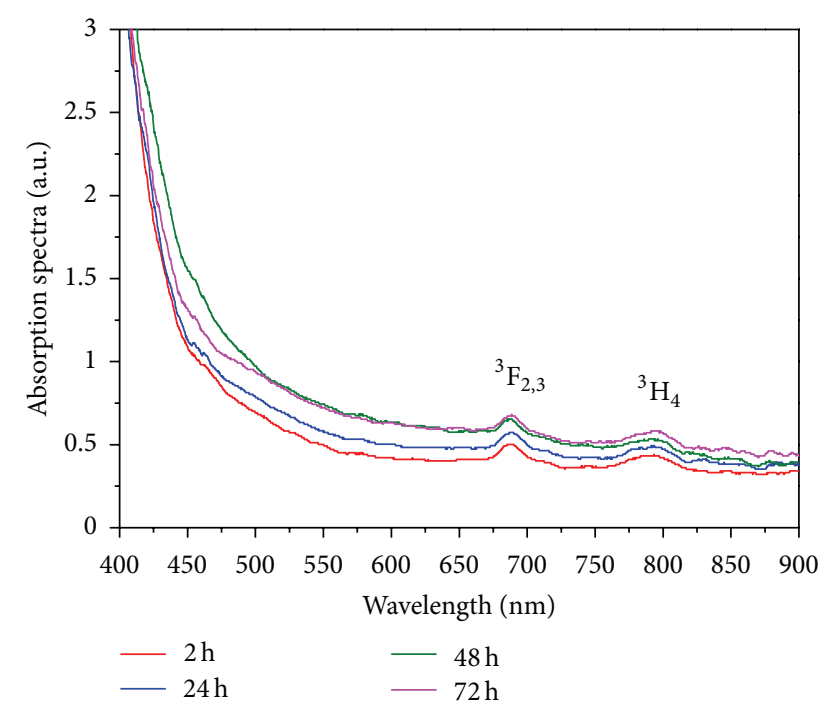

FIgURE 9: Absorption spectra of TZO-Tm:Ag glasses for different heat-treatment times [3].

and $662 \mathrm{~nm}$ that correspond, respectively, to the transitions ${ }^{2} \mathrm{H}_{11 / 2} \rightarrow{ }^{4} \mathrm{I}_{15 / 2},{ }^{4} \mathrm{~S}_{3 / 2} \rightarrow{ }^{4} \mathrm{I}_{15 / 2}$, and ${ }^{4} \mathrm{~F}_{9 / 2} \rightarrow{ }^{4} \mathrm{I}_{15 / 2}$ can be seen in Figure 6(a). Figure 6(b) shows that the relative intensity of the upconversion bands can be adjusted by an appropriate choice of the HT time that controls the amount of silver NPs formed in the sample.

The LSPR band is not observed in Figure 5 because the amount of silver NPs is not enough to originate a strong band. However, we estimate, with basis on the dielectric function of silver [19], that $\lambda_{\mathrm{SP}}$ is located between $\approx 400$ and $\approx 500 \mathrm{~nm}$, as shown in the Figure 1(a). However, the presence of silver NPs in the samples is confirmed by the TEM images shown in Figure 7.

The emission peaks observed in the spectra of the Figure $6(\mathrm{a})$ are due the transitions indicated in the simplified energy level diagram for the $\mathrm{Er}^{3+}$ and the $\mathrm{Yb}^{3+}$ ions in Figure 8 . The proximity between the green PL wavelengths and the LSPR favors the PL intensity enhancement. The red emission is also intensified for larger values of annealing times and this is attributed to the nucleation of larger silver NPs and aggregates.

The ratio between the integrated intensities of transitions centered at $525 \mathrm{~nm}$ and $550 \mathrm{~nm}$ changes from 0.77 ( $\mathrm{HT} \approx 0 \mathrm{~h}$ ) to $\approx 1.0(\mathrm{HT} \approx 50 \mathrm{~h}$ ) because the transition at $525 \mathrm{~nm}$ is closest to the estimated LSPR wavelength than $550 \mathrm{~nm}$.

In summary, with the present results we demonstrated the simultaneous exploitation of the enhanced local field contribution due to silver NPs and energy transfer processes between two different RE ions in order to control the PL spectrum of the glassy composite material. This approach can be applied for different RE ions in order to improve the efficiency of luminescent displays.

3.3. Frequency Upconversion in Bulk TZO-Tm:Ag and TWB$E r: A g$. The frequency upconversion properties of $\mathrm{Tm}^{3+}$ doped $\mathrm{TeO}_{2}-\mathrm{ZnO}$ glasses containing silver nanoparticles was

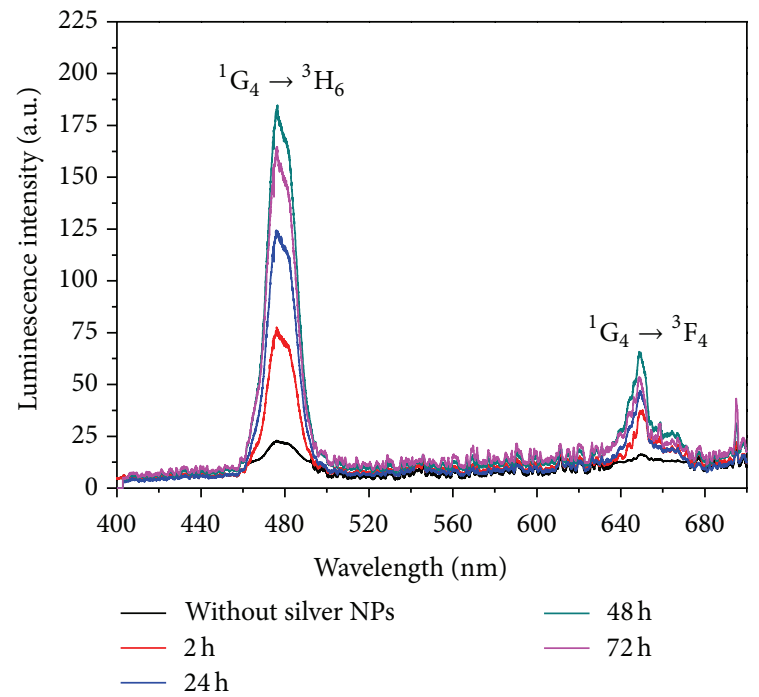

(a)

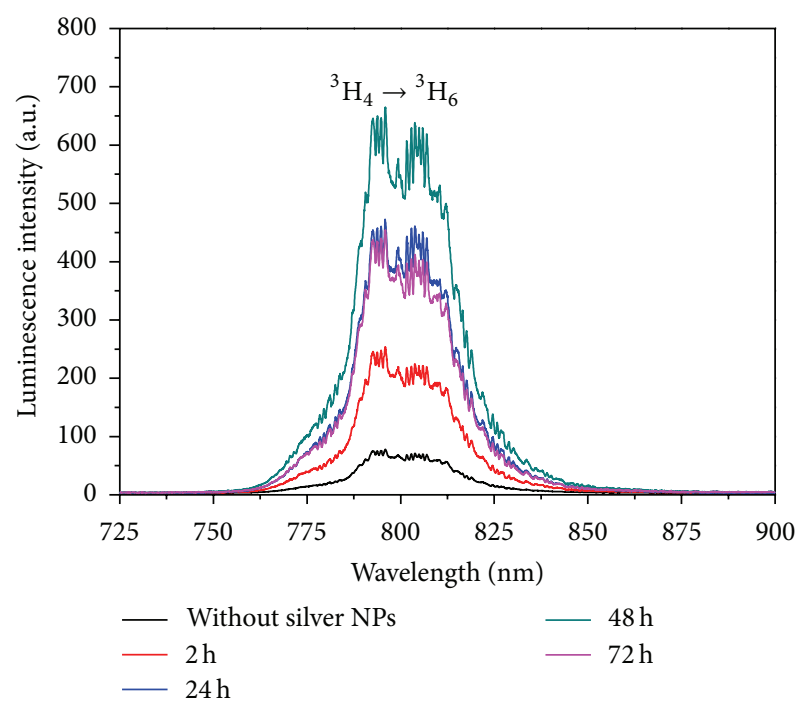

(b)

FIgURE 10: Emission spectra of TZO-Tm:Ag glasses for different heat-treatment times [3].

reported for the first time in [3]. For excitation, we used a laser operating at $1050 \mathrm{~nm}$. The influence of the silver NPs in the infrared-to-visible and infrared-to-infrared upconversion processes associated to the $\mathrm{Tm}^{3+}$ ions was studied. Absorption and emission spectra of the TZO-Tm:Ag samples heattreated for different HT times are shown in Figures 9 and 10, respectively.

As in the previous case (Section 3.2), the LSPR band is not observed because the amount of NPs is not enough to show a noticeable band. We estimated that the $\lambda_{\mathrm{SP}}$ of isolated NPs to be located in the range 400 to $500 \mathrm{~nm}$ because PGO and TZO have dielectric functions of approximate values; the presence of silver NPs is confirmed by the TEM image presented in Figure 11 . 


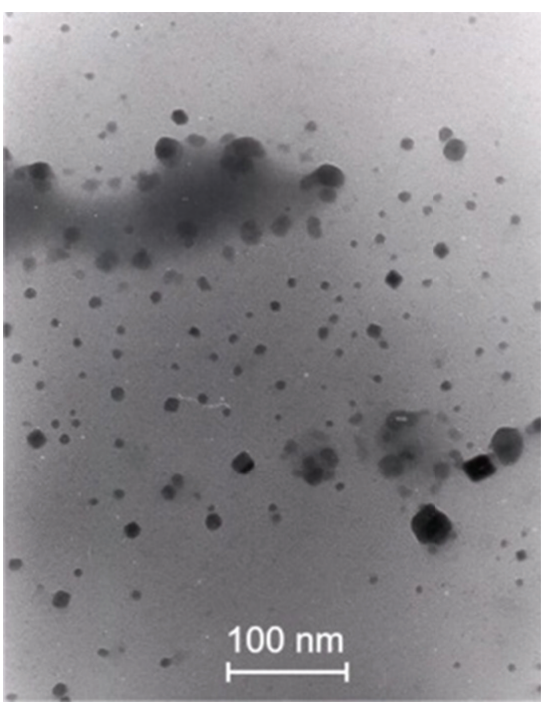

FIGURE 11: TEM images of the samples heat-treated during $48 \mathrm{~h} \mathrm{[3].}$

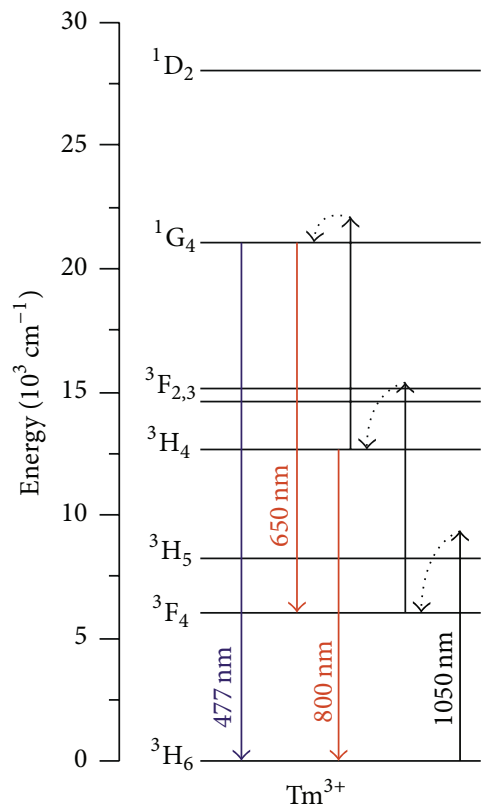

FIGURE 12: Simplified energy level diagram of $\mathrm{Tm}^{3+}$ ions with indication of the upconversion pathways and wavelengths [3].

Figure 12 presents a simplified energy diagram for the $\mathrm{Tm}^{3+}$ ions with indication of the excitation pathways and the PL transitions observed.

One order of magnitude enhancement is observed for the whole PL spectra that is a remarkable result. The spectra corresponding to HT during 72 hours show partial quenching of the PL intensity as reported for other samples.

The dependence of the upconversion signals with the laser intensity was analyzed to identify the routes corresponding to each upconversion emission. The log-log plots of the upconversion intensities corresponding to transitions ${ }^{1} \mathrm{G}_{4} \rightarrow$ ${ }^{3} \mathrm{H}_{6},{ }^{1} \mathrm{G}_{4} \rightarrow{ }^{3} \mathrm{~F}_{4}$ and ${ }^{3} \mathrm{H}_{4} \rightarrow{ }^{3} \mathrm{H}_{6}$ present slopes of $\approx 2.7, \approx 2.8$,

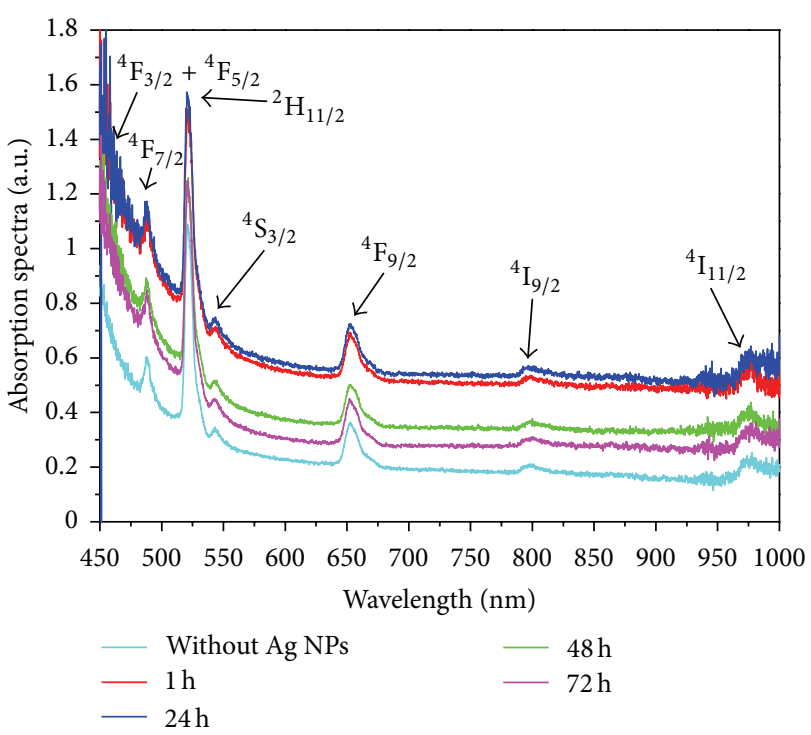

FIGURE 13: Absorption spectra of TBW-Er:Ag glasses for different heat-treatment times [4].

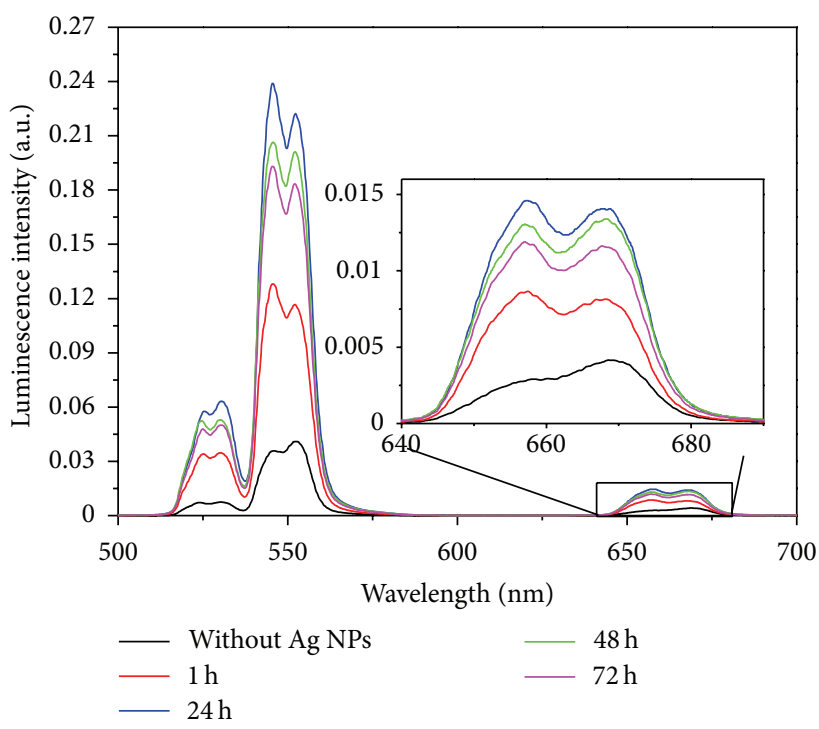

FIGURE 14: Emission spectra of TBW-Er:Ag glasses for different heat-treatment times [4].

and $\approx 1.8$, respectively. These results indicate that the PL bands at $477 \mathrm{~nm}$ and $650 \mathrm{~nm}$ are due to the absorption of three laser photons, while the transition ${ }^{3} \mathrm{H}_{4} \rightarrow{ }^{3} \mathrm{H}_{6}$ is due to the absorption of two photons. Considering the mismatch between the incident photon energy and the energy levels, we conclude that the upconversion processes occur because the intermediate steps are phonon-assisted. Even the excited state absorption ${ }^{3} \mathrm{~F}_{4} \rightarrow{ }^{3} \mathrm{~F}_{2,3}$ which is resonant is followed by emission of phonons due to the decay from level ${ }^{3} \mathrm{~F}_{2,3}$ to the level ${ }^{3} \mathrm{H}_{4}$.

The influence of the Ag NPs on the upconversion emission of the TBW-Er:Ag glass was investigated using a laser operating at $980 \mathrm{~nm}$ in resonance with transition ${ }^{4} \mathrm{I}_{15 / 2}{ }^{-4} \mathrm{I}_{9 / 2}$ 


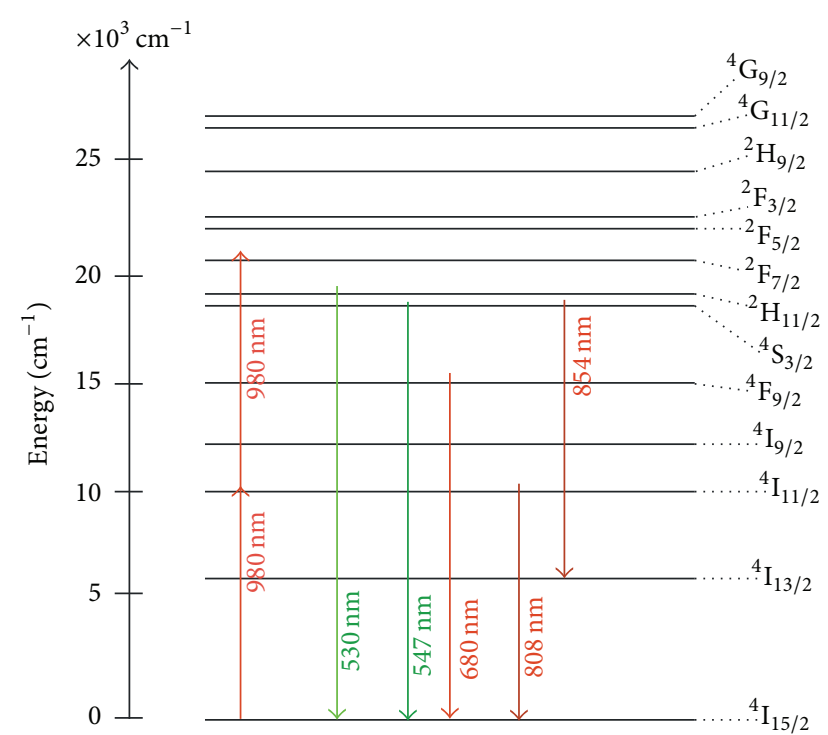

FIGURE 15: Simplified Er energy levels diagram illustrating theupconversion process by energy transfer and by excited state absorption.

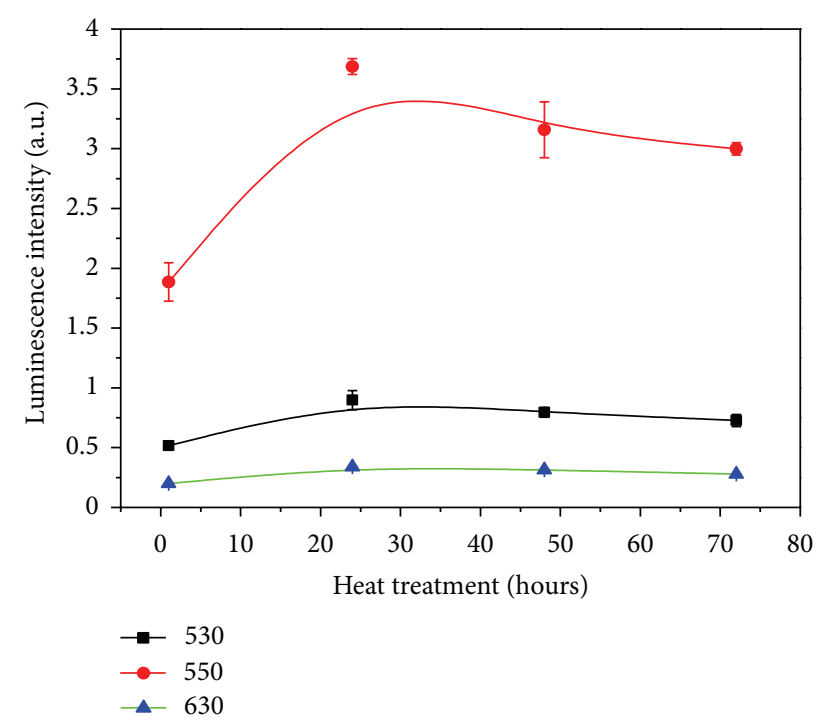

FIGURE 16: Dependence of the upconverted signals on the heat treatment corresponding to ${ }^{2} \mathrm{H}_{11 / 2} \rightarrow{ }^{4} \mathrm{I}_{15 / 2}$ and ${ }^{4} \mathrm{~F}_{9 / 2} \rightarrow{ }^{4} \mathrm{I}_{15 / 2}$ transitions [4].

[4]. Absorption and PL spectra of the samples heat-treated for different time intervals are shown in Figures 13 and 14, respectively. A simplified $\mathrm{Er}^{3+}$ energy diagram showing possible process related to the absorption of the laser energy is shown in Figure 15.

By comparing the emission spectra of the sample without silver NPs with the sample heat-treated during $24 \mathrm{~h}$ it can be seen that the ${ }^{2} \mathrm{H}_{11 / 2} \rightarrow{ }^{4} \mathrm{I}_{15 / 2},{ }^{4} \mathrm{~S}_{3 / 2} \rightarrow 2{ }^{4} \mathrm{I}_{15 / 2}$ and ${ }^{4} \mathrm{~F}_{9 / 2} \rightarrow$ ${ }^{4} \mathrm{I}_{15 / 2}$ transitions increased by $\approx 700 \%$. For HT during $48 \mathrm{~h}$ and $72 \mathrm{~h}$, quenching of the PL is observed. The dependence of the upconverted intensities exhibited a quadratic dependence with the laser intensity and the dependence with the HT time is shown in Figure 16.

Figure 17 shows TEM images of a sample after HT during $24 \mathrm{~h}$. The black spots are due to the silver NPs which have average size of about $40 \mathrm{~nm}$. A small amount of silver NPs was observed with average diameter of $\approx 10 \mathrm{~nm}$. The electron diffraction pattern is also shown in the inset.

The results presented in this section demonstrate that the approach of increasing PL of rare-earth doped tellurite glasses by nucleation of metallic NPs can be successful also for this glass family that has proved already its importance for photonic applications.

3.4. Stokes and Antistokes Luminescence of BGO-Er:Si. The first observation of PL enhancement in BGO-Er:Si excited at $980 \mathrm{~nm}$ was reported in [5]. The samples fabricated presented large concentration of Si NPs with sizes varying from 2 to $10 \mathrm{~nm}$ as it is illustrated in Figure 18 for the samples heattreated during $3 \mathrm{~h}$ and $72 \mathrm{~h}$.

Figures 19 and 20 present absorption and emission spectra of the samples studied including results for a sample without Si NPs used as reference sample. The PL signals were obtained by excitation of transition ${ }^{4} \mathrm{I}_{15 / 2}{ }^{4} \mathrm{I}_{9 / 2}$.

Absorption bands associated with $\mathrm{Er}^{3+}$ ions are observed as well as a broad absorption band in the range $450-550 \mathrm{~nm}$ that was ascribed to the electronic transition ${ }^{2} \mathrm{P}_{1 / 2} \rightarrow{ }^{2} \mathrm{P}_{3 / 2}$ of $\mathrm{Bi}^{2+}$ ions, according to the literature $[23,24]$. A partial quenching of the $\mathrm{Er}^{3+}$ transitions ${ }^{4} \mathrm{I}_{15 / 2} \rightarrow{ }^{2} \mathrm{H}_{11 / 2}$ and ${ }^{4} \mathrm{I}_{15 / 2} \rightarrow{ }^{4} \mathrm{~F}_{7 / 2}$ due to the presence of the $\mathrm{Bi}^{2+}$ ions can be observed. However, the quenching is reduced in the samples heat-treated during longer times. The PL band in the infrared region, centered at $1530 \mathrm{~nm}$, is due to the ${ }^{4} \mathrm{I}_{13 / 2} \rightarrow{ }^{4} \mathrm{I}_{15 / 2}$ transition. The $\mathrm{Er}^{3+}$ transitions that correspond to all PL bands are indicated in Figure 15. Note that the signal at $545 \mathrm{~nm}$ is enhanced by $\approx 200 \%$ for the sample heat-treated during 72 hours. For the other emissions centered at $525 \mathrm{~nm}$, $660 \mathrm{~nm}$, and $1530 \mathrm{~nm}$, we observed $\approx 100 \%$ enhancement in the PL amplitudes for the samples heat-treated during 72 hours. In addition, although the PL spectrum becomes stronger for longer heat-treatment time, the bands' profiles do not change. These results indicate that a large fraction of the $\mathrm{Er}^{3+}$ ions are located near the interfaces between the Si NPs and the germanate matrix. This is in accordance with [25] that showed a low solubility of $\mathrm{Er}^{3+}$ in $\mathrm{Si}$.

The laser intensity dependence of the visible PL bands indicates that in the upconversion process two laser photons are converted to one photon with larger frequency, while the behavior of the near-infrared emission is a simple downconversion process involving the absorption of only one laser photon as illustrated in Figure 21.

Three mechanisms may contribute for the enhancement of the antistokes emission due to the presence of the Si NPs. One mechanism may be the stepwise absorption of laser photons by the Si NPs with subsequent ET from doubleexcited Si NPs to $\mathrm{Er}^{3+}$ ions in the ground state. An other possible excitation pathway involves ET from two singlephoton excited Si NPs to one $\mathrm{Er}^{3+}$ ion initially in the ground 

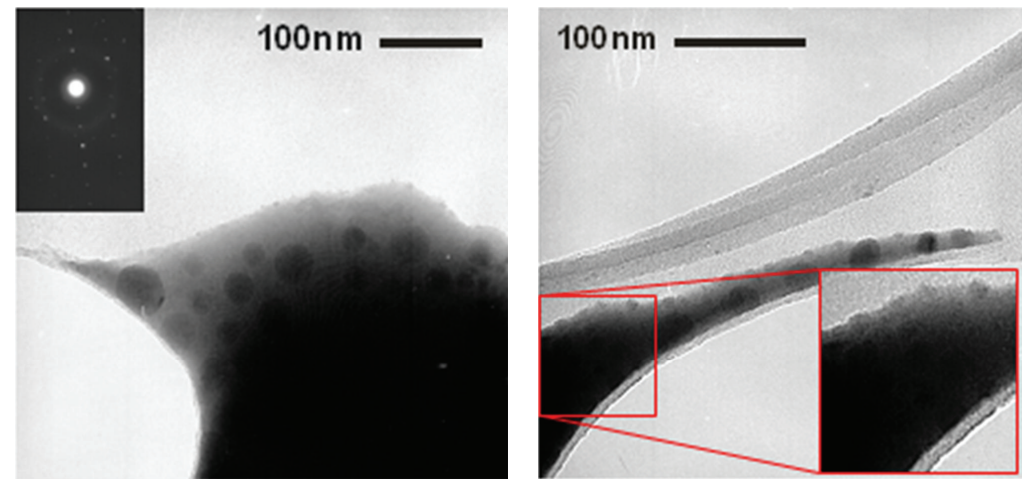

FIgURE 17: Transmission electron microscope images of TBW-Er:Ag sample with silver NPs after heat-treatment of $24 \mathrm{~h}$ [4].

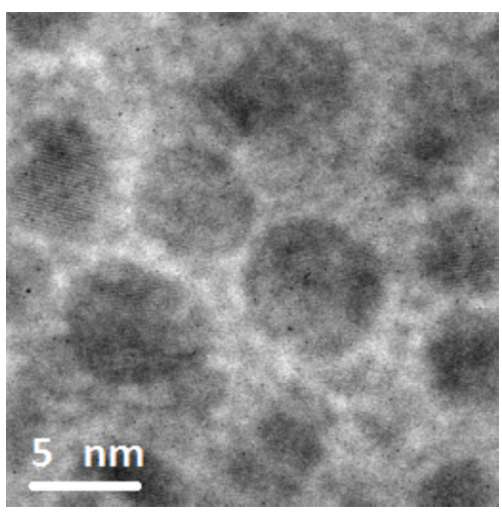

(a)

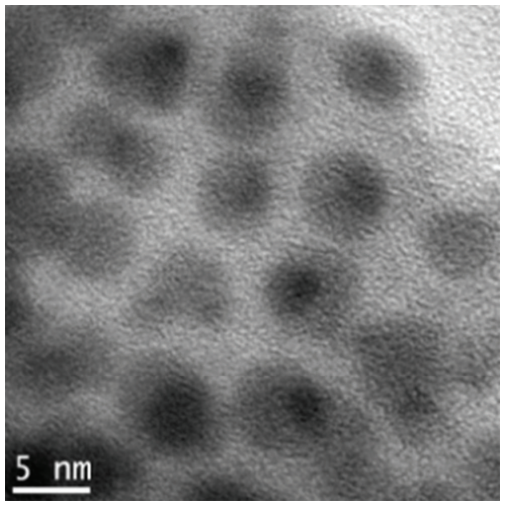

(b)

FIGURE 18: TEM images of Si NPs in $\mathrm{Er}^{3+}$ doped $\mathrm{GeO}_{2}-\mathrm{Bi}_{2} \mathrm{O}_{3}$ glasses heat-treated during $3 \mathrm{~h} \mathrm{(a)} \mathrm{and} \mathrm{during} 72 \mathrm{~h} \mathrm{(b)} \mathrm{[5].}$

state. The third possibility is the energy transfer from single Si NPs to erbium ions already excited by the incident laser to level ${ }^{4} \mathrm{I}_{11 / 2}$. These three processes should be considered because of the large density of Si NPs in the samples. However, at the present stage of the work, it is not possible to identify

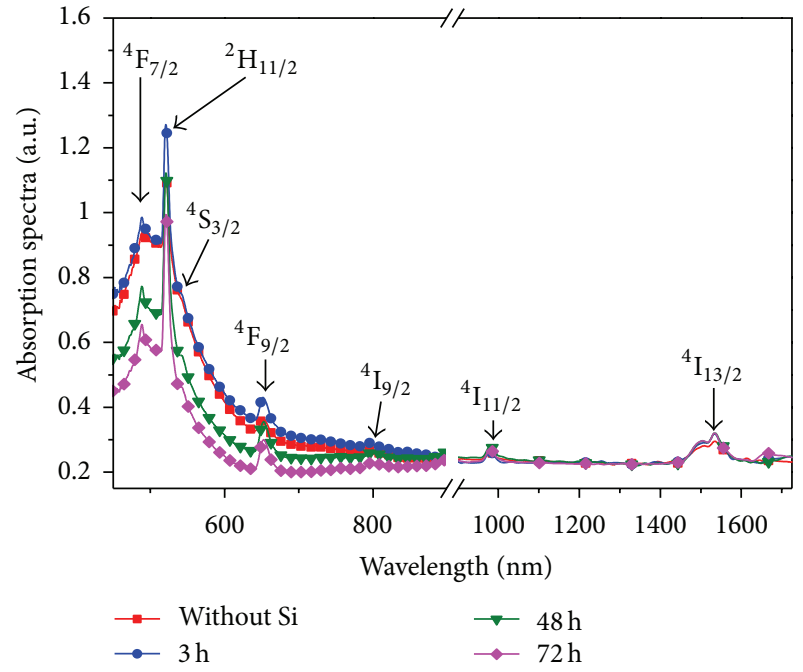

Figure 19: Absorption spectra of $\mathrm{Er}^{3+}$ doped $\mathrm{GeO}_{2}-\mathrm{Bi}_{2} \mathrm{O}_{3}$ glass heat-treated during different time intervals to nucleate $\mathrm{Si}$-NPs. The spectrum of a sample without NPs is shown for reference [5].

the actual mechanism contributing for the upconversion enhancement.

3.5. Third-Order Nonlinearity of PGO:Au Films. In order to exploit the large potential of germanate glasses for integrated optics, we developed a technique to produce PGO films containing silver NPs [26]. Radiofrequency cosputtering was used for deposition of noncrystalline films on silica substrates. The parameters of the fabrication process and the influence of the HT on the optical properties of the films were investigated. Good quality PGO films were produced and their nonlinear response was studied. In this section, we report on the third-order optical properties of PGO films containing gold NPs (PGO:Au).

Figure 22(a) shows the absorption spectra of films without compensation of the Fresnel reflection contribution. 


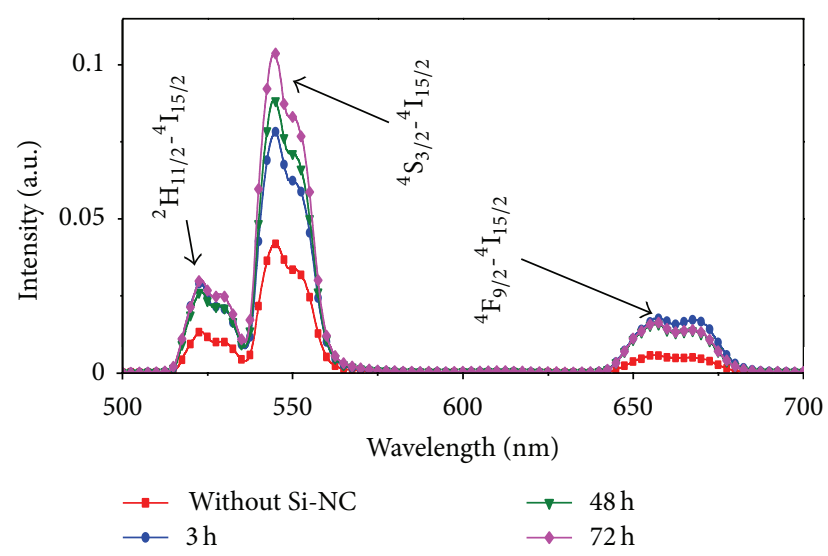

(a)

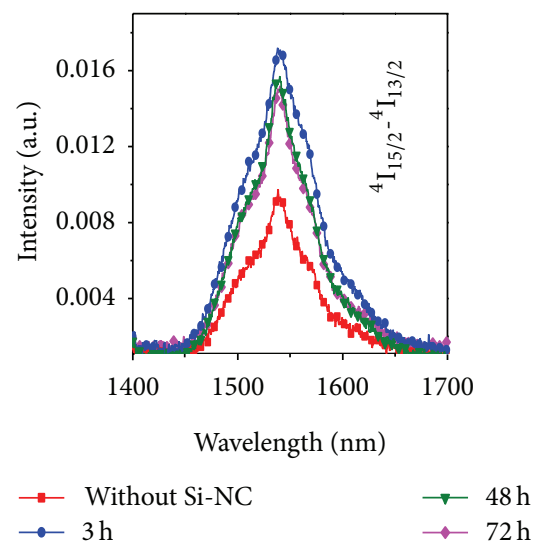

(b)

Figure 20: Emission spectra of the $\mathrm{Er}^{3+}$ doped $\mathrm{GeO}_{2}-\mathrm{Bi}_{2} \mathrm{O}_{3}$ glass with $\mathrm{Si}$ NPs heat-treated during different time intervals. (a) Infraredto-visible frequency upconversion. (b) Frequency downconversion [5].

Notice that while the spectrum of the glass film without gold NPs is almost flat along the whole wavelength range, a strong absorption band centered at $\approx 575 \mathrm{~nm}(1.96 \mathrm{eV})$ is observed in the PGO: Au film due to the LSPR of the gold NPs. Figure 22(b) shows a TEM image of the sample and Figure 22(c) presents the size distribution histogram of the NPs that have average diameter of $16 \mathrm{~nm}$.

Figure 23 shows Z-scan profiles for the films with and without gold. The Z-scan technique allows measurements of the third-order susceptibility of materials [20]. From the closed aperture Z-scan profile, the amplitude and signal of the nonlinear refractive index $n_{2}$ are determined. A typical Z-scan profile of the film with gold is shown in Figure 23(a) indicating a focusing nonlinearity $\left(n_{2}>0\right)$, while the inset in the figure shows the result for the film without gold NPs that has negligible nonlinearity. Figure 23(b) shows an open aperture Z-scan profile for the film with gold NPs and the inset shows negligible nonlinear absorption for the film without gold. This measurement allows obtaining the nonlinear absorption coefficient $\alpha_{2}$. The solid lines represent the theoretical fitting to the experimental data based on the procedure introduced in [20].

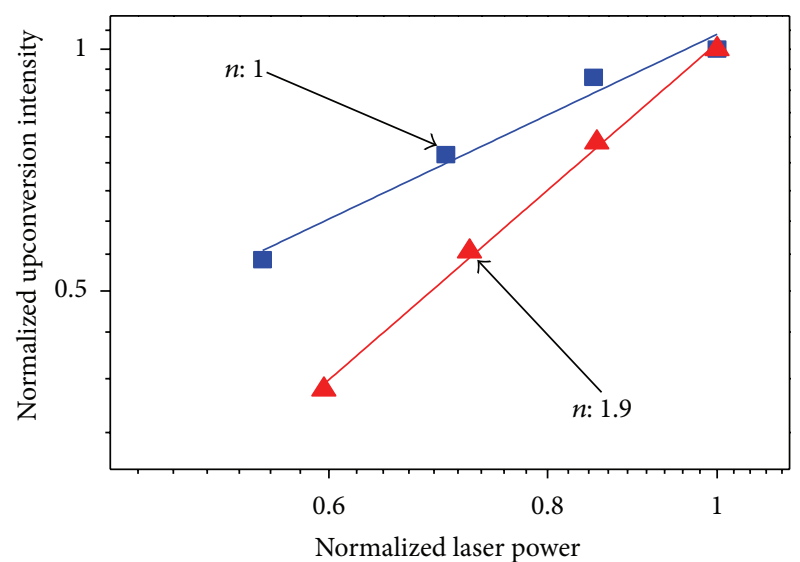

FIGURE 21: Integrated luminescence intensity as a function of the laser intensity [5].

The values of $n_{2}=(6 \pm 1) \times 10^{-10} \mathrm{~cm}^{2} / \mathrm{W}$ measured at $532 \mathrm{~nm}$ and $\alpha_{2}=(1.7 \pm 0.3) \times 10^{4} \mathrm{~cm} / \mathrm{GW}$ are attributed to the NPs contribution, since we did not observe nonlinear signals in the film without gold. Carbon disulfide $\left(\mathrm{CS}_{2}\right)$, in a cell of $1 \mathrm{~mm}$ length, was used as standard calibration material with $n_{2}=3.1 \times 10^{-14} \mathrm{~cm}^{2} / \mathrm{W}$ [27].

The nonlinear birefringence induced in a pump-probe experiment using a Kerr gate setup was also studied using a laser operating at $800 \mathrm{~nm}$ (pulses of $150 \mathrm{fs}$ at $76 \mathrm{MHz}$ ). Figure 24 shows the behavior of the normalized Kerr gate signal of film with gold NPs as a function of the delay time between the pump and probe pulses.

The signal corresponding to $\mathrm{CS}_{2}$, with two decay times: a fast decay of $<50 \mathrm{fs}$ and a slow one of $\approx 2 \mathrm{ps}$, is also shown to illustrate the time resolution of the apparatus. The symmetric signal obtained with the PGO:Au film indicates that the nonlinearity is faster than the laser pulse duration. Also, by measuring the behavior of the probe beam signal as a function of the pump beam intensity, we obtained $n_{2}=(10 \pm 2) \times$ $10^{-13} \mathrm{~cm}^{2} / \mathrm{W}$. In addition, we investigated the transmittance of the film as a function of the laser intensity. No changes of the transmitted intensity was detected indicating that $\alpha_{2}$ was smaller than the sensitivity of the setup $(<60 \mathrm{~cm} / \mathrm{GW})$.

The nonlinear experiments revealed ultrafast response of the film with gold NPs and enhanced values of the nonlinear refractive index at 532 and $800 \mathrm{~nm}$ due to the presence of gold NPs. A large nonlinear absorption coefficient was measured at $532 \mathrm{~nm}$ indicating the possible use of the films for optical limiting in the picosecond regime. The HT of the films improved the figure of merit for all-optical switching in comparison with the results obtained with the films without gold NPs by two orders of magnitude at $800 \mathrm{~nm}$ [6].

\section{Conclusion}

In conclusion, considerable progress has been made over the last decade on obtaining efficient luminescent composites from germanate and tellurite glasses doped with rareearth ions containing metallic and semiconductor nanoparticles. The work has led to the production of good optical 


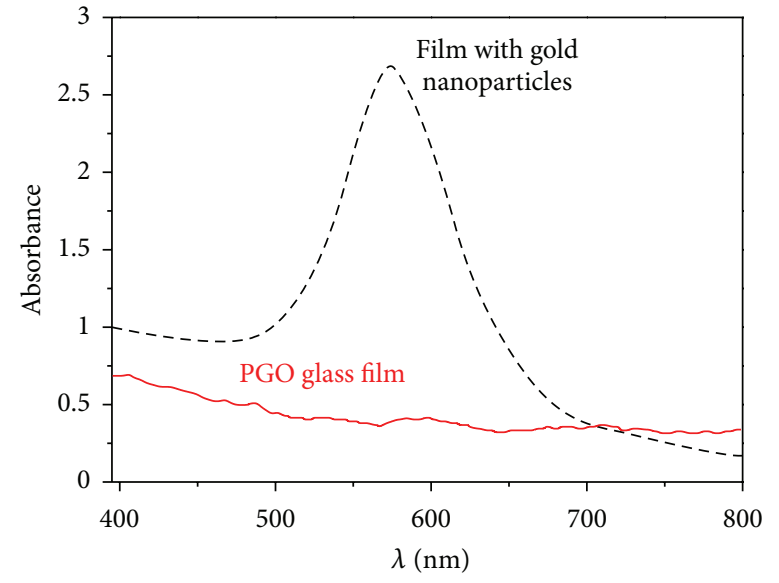

(a)

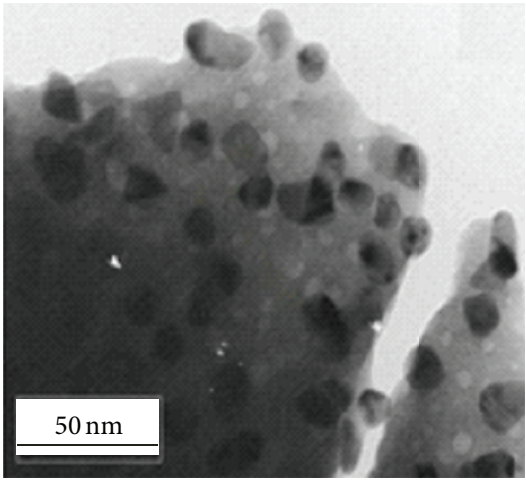

(b)

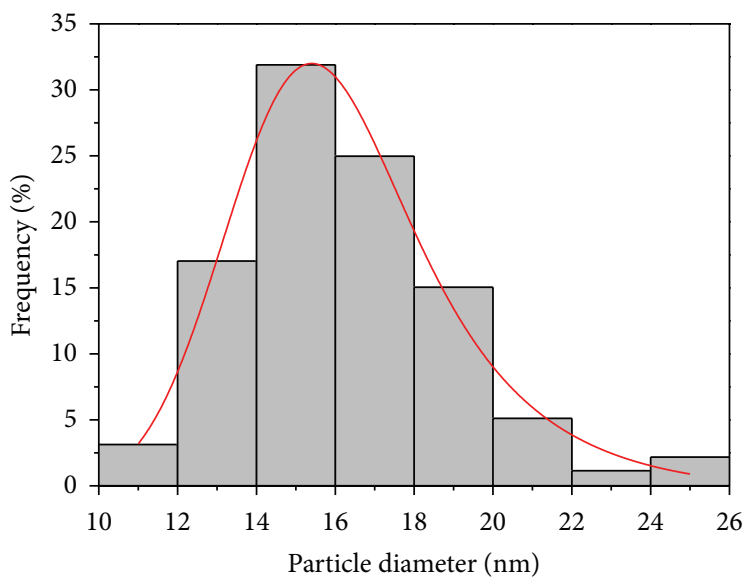

(c)

FIGURE 22: (a) Absorbance spectra of the PGO film with and without gold NPs at room temperature (films thickness: $1.1 \mu \mathrm{m}$ ). (b) TEM image of the PGO:Au film. (c) Size distribution histogram of the gold NPs [5].

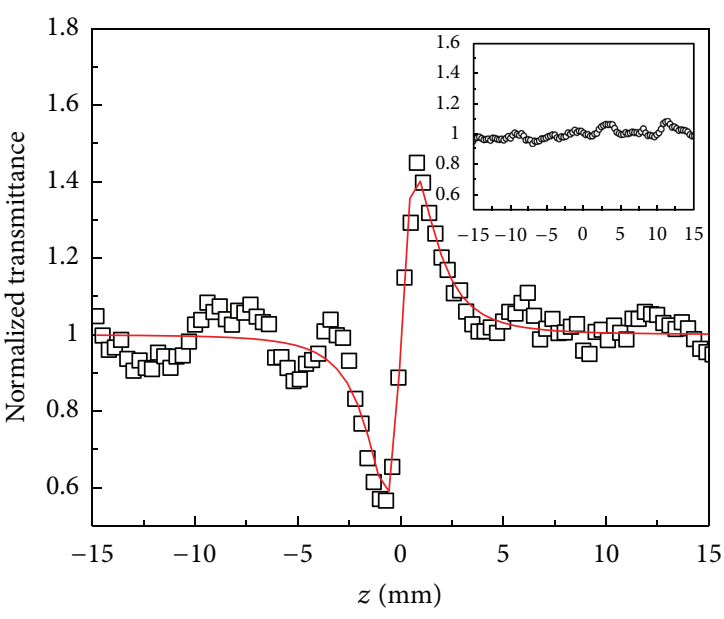

(a)

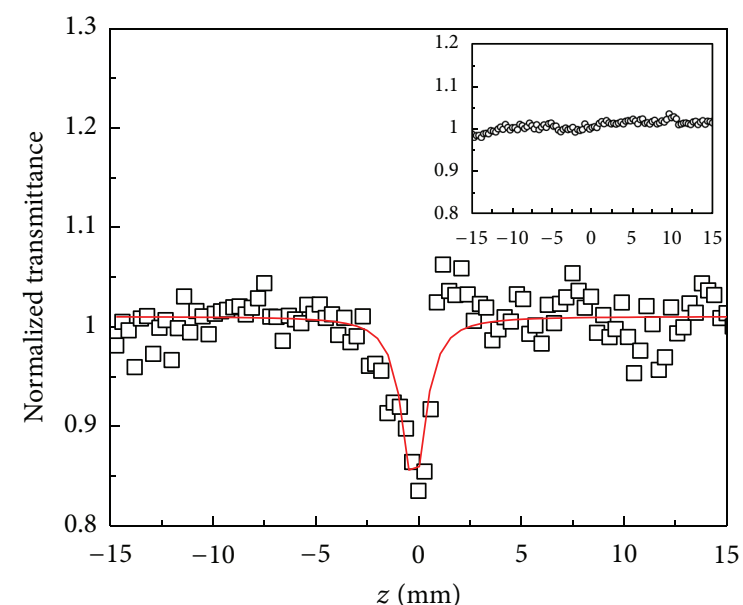

(b)

FIGURE 23: Z-Scan traces of the film with gold NPs at $532 \mathrm{~nm}$ (open squares). (a) Nonlinear refraction; (b) nonlinear absorption. The results for the film without gold (open circles) are shown in the insets. Laser intensity: $560 \mathrm{MW} / \mathrm{cm}^{2}$ [27]. 


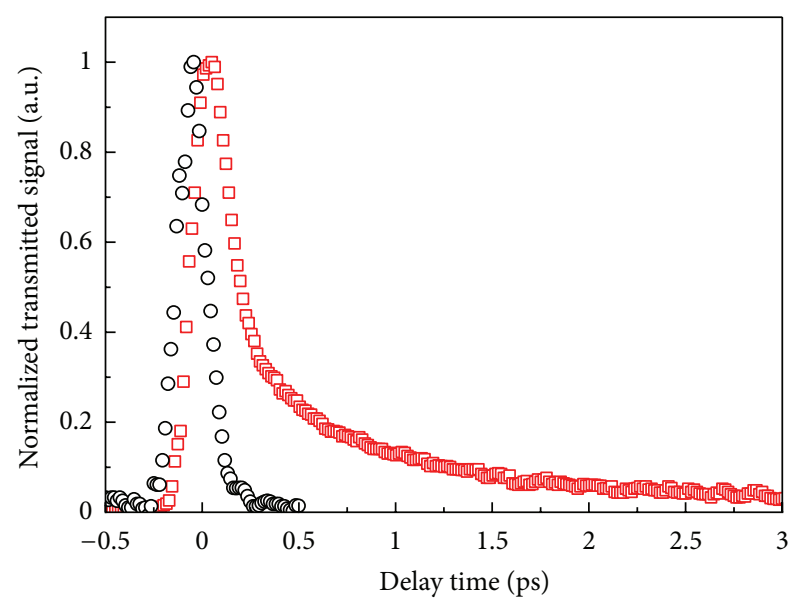

FIGURE 24: Normalized Kerr gate signal for $\mathrm{CS}_{2}$ (open squares) and for the film with gold NPs (open circles). Laser wavelength: $800 \mathrm{~nm}$. Beams' intensities: $I_{\text {pump }}=342 \mathrm{MW} / \mathrm{cm}^{2}$ and $I_{\text {probe }}=45 \mathrm{MW} / \mathrm{cm}^{2}$. [27].

quality samples that present appropriate characteristics for photoluminescence-based devices. The possibilities to extend the work towards development of nonlinear optical composites are large, and we expect to be successful obtaining efficient materials for nonlinear photonics in the future.

\section{Acknowledgments}

This work was supported by the Conselho Nacional de Desenvolvimento Científico e Tecnológico (CNPq) through the National Institute of Photonics (INCT Project) and by a grant from CNPq and FACEPE (Fundação de Amparo à Ciência do Estado de Pernambuco) through the PRONEX program.

\section{References}

[1] L. R. P. Kassab, D. S. Da Silva, and C. B. de Araújo, "Influence of metallic nanoparticles on electric-dipole and magnetic-dipole transitions of $\mathrm{Eu}^{3+}$ doped germanate glasses," Journal of Applied Physics, vol. 107, no. 11, Article ID 113506, 2010.

[2] L. R. P. Kassab, F. A. Bomfim, J. R. Martinelli, N. U. Wetter, J. J. Neto, and C. B. de Araújo, "Energy transfer and frequency upconversion in $\mathrm{Yb}^{3+}$ - $\mathrm{Er}^{3+}$-doped $\mathrm{PbO}-\mathrm{GeO}_{2}$ glass containing silver nanoparticles," Applied Physics B, vol. 94, no. 2, pp. 239242, 2009.

[3] T. A. A. de Assumpção, D. M. da Silva, M. E. Camilo et al., "Frequency upconversion properties of $\mathrm{Tm}^{3+}$ doped $\mathrm{TeO}_{2}-\mathrm{ZnO}$ glasses containing silver nanoparticles," Journal of Alloys and Compounds, vol. 536, supplement 1, pp. S504-S506, 2012.

[4] V. P. P. de Campos, L. R. P. Kassab, T. A. A. de Assumpção, D. S. da Silva, and C. B. de Araújo, "Influence of silver nanoparticles on the upconversion emission of $\mathrm{TeO}_{2}-\mathrm{WO}_{3}-\mathrm{Bi}_{2} \mathrm{O}_{3}$ glasses doped with $\mathrm{Er}^{3+}$," Journal of Applied Physics, vol. 112, Article ID 063519, 2012.

[5] D. S. da Silva, L. P. Naranjo, L. R. P. Kassab, and C. B. de Araújo, "Photoluminescence from germanate glasses containing silicon nanocrystals and erbium ions," Applied Physics B, vol. 106, no. 4, pp. 1015-1018, 2012.

[6] C. B. de Araújo, T. R. Oliveira, E. L. Falcão-Filho, D. M. da Silva, and L. R. P. Kassab, "Nonlinear optical properties of $\mathrm{PbO}-\mathrm{GeO}_{2}$ films containing gold nanoparticles," Journal of Luminescence, vol. 133, pp. 180-183, 2013.

[7] M. Yamane and Y. Asahara, Glasses for Photonics, Cambridge University Press, Cambridge, UK, 2000.

[8] O. Yasutake, "Recent progress in optics and photonics materials characteristics of tellurites glasses as novel fiber raman gain media," Ceramics Japan, vol. 41, no. 9, pp. 698-702, 2006.

[9] M. J. F. Digonnet, Rare Earth Doped Fiber Lasers and Amplifiers, Marcel Dekker, New York, NY, USA, 1993.

[10] L. R. P. Kassab and C. B. de Araújo, "Germanate and tellurite glasses for photonic applications," in Photonics Research Developments, chapter 13, p. 385, Nova Science, New York, NY, USA, 2008.

[11] T. A. A. de Assumpção, L. R. P. Kassab, A. S. L. Gomes, C. B. de Araújo, and N. U. Wetter, "Influence of the heat treatment on the nucleation of silver nanoparticles in $\mathrm{Tm}^{3+}$ doped $\mathrm{PbO}-\mathrm{GeO}_{2}$ glasses," Applied Physics B, vol. 103, pp. 165-169, 2011.

[12] Y. Chen, Q. Nie, T. Xu, S. Dai, X. Wang, and X. Shen, "A study of nonlinear optical properties in $\mathrm{Bi}_{2} \mathrm{O}_{3}-\mathrm{WO}_{3}-\mathrm{TeO}_{2}$ glasses," Journal of Non-Crystalline Solids, vol. 354, no. 29, pp. 3468-3472, 2008.

[13] A. J. Kenyon, P. F. Trwoga, M. Federighi, and C. W. Pitt, "Optical properties of PECVD erbium-doped silicon-rich silica: evidence for energy transfer between silicon microclusters and erbium ions," Journal of Physics Condensed Matter, vol. 6, no. 21, pp. L319-L324, 1994.

[14] M. Fujii, M. Yoshida, Y. Kanzawa, S. Hayashi, and K. Yamamoto, "1.54 $\mu \mathrm{m}$ photoluminescence of $\mathrm{Er}^{3+}$ doped into $\mathrm{SiO}_{2}$ films containing Si nanocrystals: evidence for energy transfer from Si nanocrystals to $\mathrm{Er}^{3+}, "$ Applied Physics Letters, vol. 71, no. 9, pp. 1198-1200, 1997.

[15] K. M. Choi, "A chemical strategy to improve the fluorescence environments of erbium-ions doped into organically modified hybrid glasses for laser amplifier applications," Materials Chemistry and Physics, vol. 103, no. 1, pp. 176-182, 2007.

[16] S. Y. Seo, M. J. Kim, and J. H. Shin, "The Nd-nanocluster coupling strength and its effect in excitation/de-excitation of $\mathrm{Nd}^{3+}$ luminescence in Nd-doped silicon-rich silicon oxide," Applied Physics Letters, vol. 83, no. 14, pp. 2778-2780, 2003.

[17] L. P. Naranjo, C. B. de Araújo, O. L. Malta, P. A. S. Cruz, and L. R. P. Kassab, "Enhancement of $\mathrm{Pr}^{3+}$ luminescence in $\mathrm{PbO}-\mathrm{GeO}_{2}$ glasses containing silver nanoparticles," Applied Physics Letters, vol. 87, no. 24, Article ID 241914, 2005.

[18] C. B. de Araújo, L. R. Kassab, R. A. Kobayashi, L. P. Naranjo, and P. A. S. Cruz, "Luminescence enhancement of $\mathrm{Pb}^{2+}$ ions in $\mathrm{TeO}_{2}$ $\mathrm{PbO}-\mathrm{GeO}_{2}$ glasses containing silver nanostructures," Journal of Applied Physics, vol. 99, Article ID 123522, 4 pages, 2006.

[19] L. A. Gómez, F. E. P. dos Santos, A. S. L. Gomes, C. B. de Araújo, L. R. P. Kassab, and W. G. Hora, "Near infrared third non linearity of $\mathrm{PbO}-\mathrm{GeO}_{2}$ films containing $\mathrm{Cu}$ and $\mathrm{CuO}_{2}$ nanoparticles," Applied Physics Letters, vol. 92, Article ID 141916, 3 pages, 2008.

[20] M. Sheik-Bahae, A. A. Said, T. H. Wei, D. J. Hagan, and E. W. Van Stryland, "Sensitive measurement of optical nonlinearities using a single beam," IEEE Journal of Quantum Electronics, vol. 26, no. 4, pp. 760-769, 1990.

[21] Y. R. Shen, Principles of Nonlinear Optics, Wiley, New York, NY, USA, 1984 
[22] P. N. Prasad, Nanophotonics, Wiley, New York, NY, USA, 2004.

[23] J. Ren, G. Dong, S. Xu, R. Bao, and J. Qiu, "Inhomogeneous broadening, luminescence origin and optical amplification in bismuth-doped glass," Journal of Physical Chemistry A, vol. 112, no. 14, pp. 3036-3039, 2008.

[24] G. Chi, D. Zhou, Z. Song, and J. Qiu, "Effect of optical basicity on broadband infrared fluorescence in bismuth-doped alkali metal germanate glasses," Optical Materials, vol. 31, no. 6, pp. 945-948, 2009.

[25] D. J. Eaglesham, J. Michel, E. A. Fitzgerald et al., "Microstructure of erbium-implanted Si," Applied Physics Letters, vol. 58, no. 24, pp. 2797-2799, 1991.

[26] D. M. da Silva, L. R. P. Kassab, J. R. Martinelli, and C. B. de Araújo, "Production and characterization of RF-sputtered $\mathrm{PbO}-\mathrm{GeO}_{2}$ amorphous thin films containing silver and gold nanoparticles," Journal of Non-Crystalline Solids, vol. 356, no. 44-49, pp. 2602-2605, 2010.

[27] R. L. Sutherland, Handbook of Nonlinear Optics, Marcel Dekker, New York, NY, USA, 2003. 

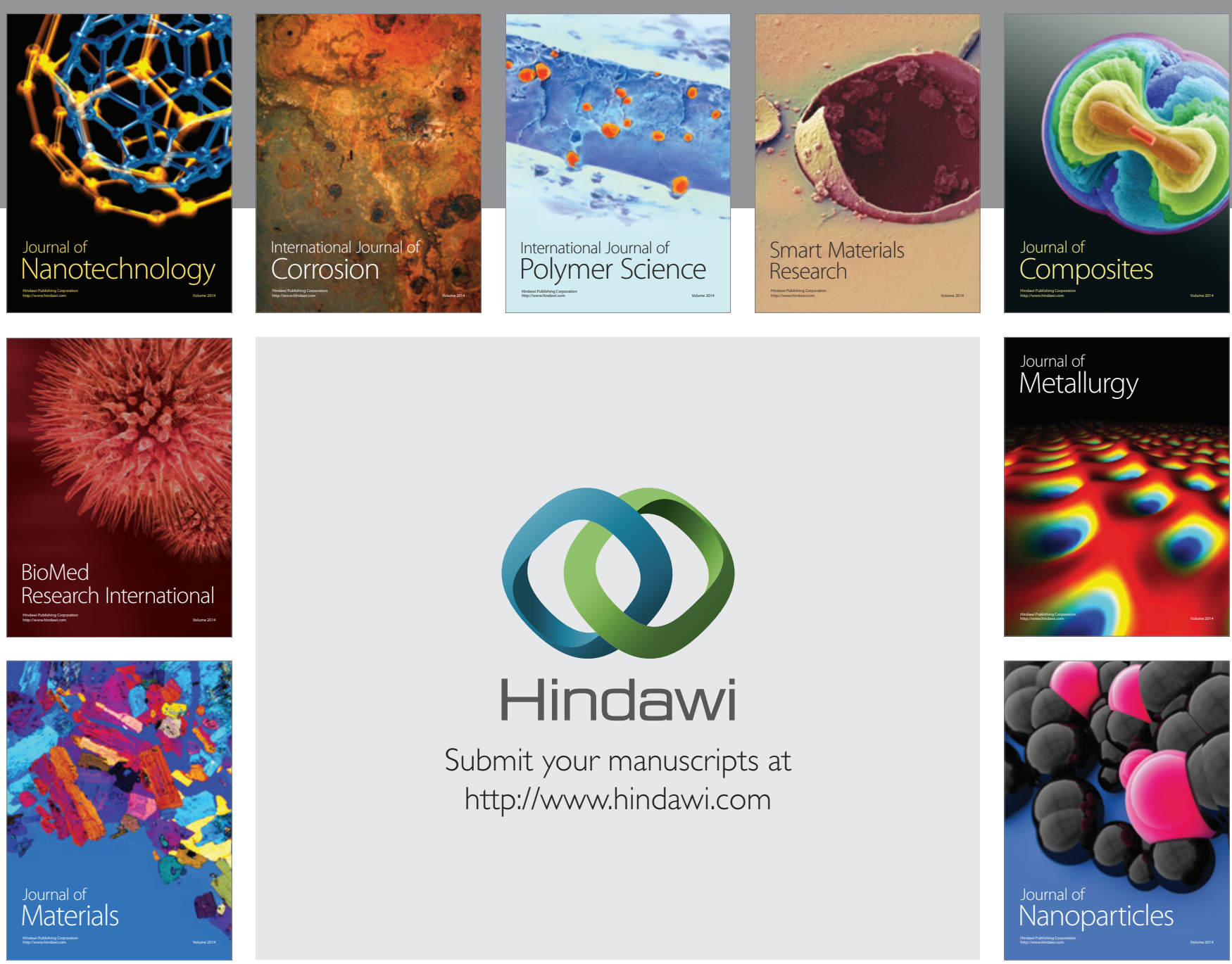

Submit your manuscripts at http://www.hindawi.com
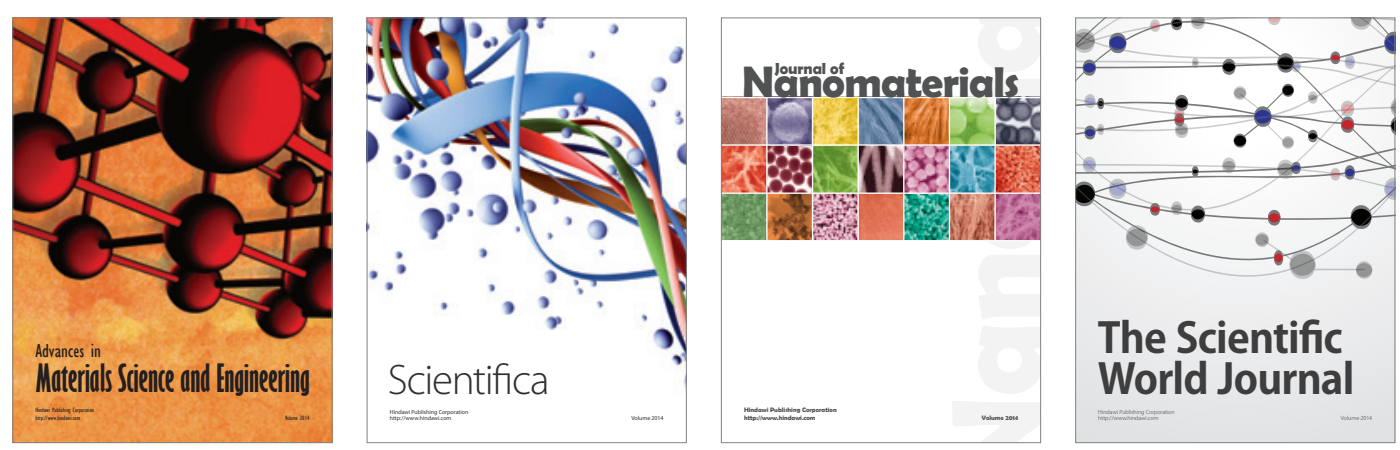

\section{The Scientific World Journal}
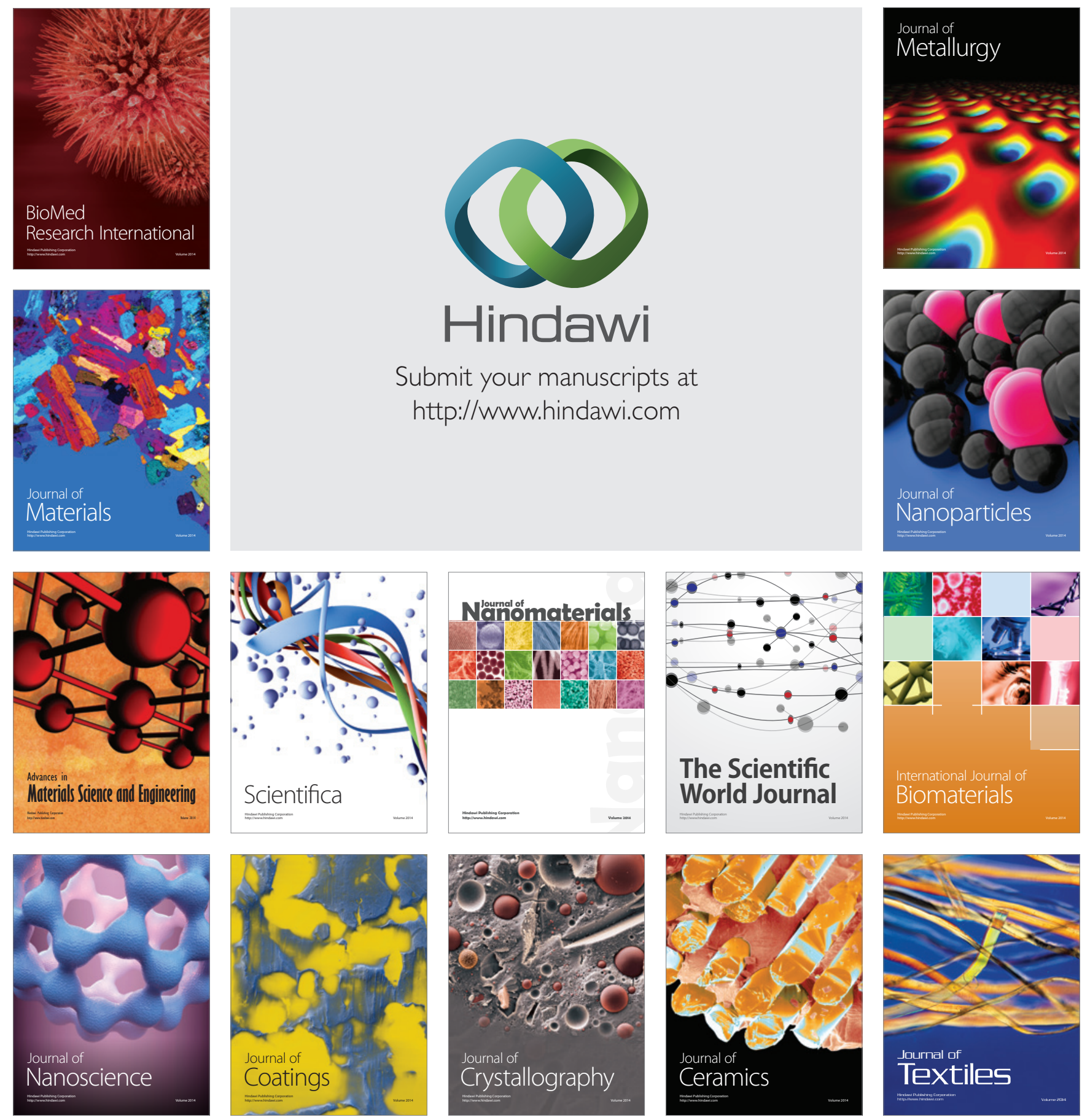